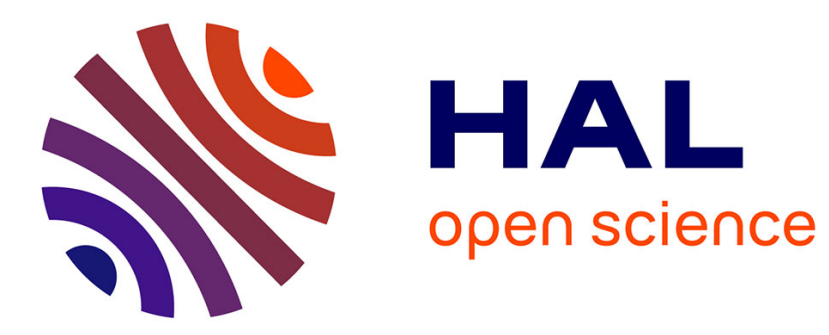

\title{
When Do We Communicate Stereotypes? Influence of the Social Context on the Linguistic Expectancy Bias
}

Daniël H. J. Wigboldus, Russell Spears, Gün R. Semin

\section{To cite this version:}

Daniël H. J. Wigboldus, Russell Spears, Gün R. Semin. When Do We Communicate Stereotypes? Influence of the Social Context on the Linguistic Expectancy Bias. Group Processes and Intergroup Relations, 2005, 8 (3), pp.215-230. 10.1177/1368430205053939 . hal-00571604

\section{HAL Id: hal-00571604 https://hal.science/hal-00571604}

Submitted on 1 Mar 2011

HAL is a multi-disciplinary open access archive for the deposit and dissemination of scientific research documents, whether they are published or not. The documents may come from teaching and research institutions in France or abroad, or from public or private research centers.
L'archive ouverte pluridisciplinaire HAL, est destinée au dépôt et à la diffusion de documents scientifiques de niveau recherche, publiés ou non, émanant des établissements d'enseignement et de recherche français ou étrangers, des laboratoires publics ou privés. 


\title{
When Do We
}

\section{Communicate Stereotypes? Influence of the Social Context on the Linguistic Expectancy Bias}

\author{
Daniël H. J. Wigboldus \\ Radboud University Nijmegen \\ Russell Spears \\ Cardiff University \\ Gün R. Semin \\ Free University, Amsterdam
}

The linguistic expectancy bias (LEB) refers to the tendency to describe expectancy consistent information at a higher level of linguistic abstraction than expectancy inconsistent information. Two experiments examined the influence of the social communicative context on the production of this linguistic bias by manipulating the group membership of the actor in, and the recipient of, stereotypical information. Results supported the prediction that an LEB effect based on stereotypes is especially pronounced in an intergroup social communicative context in which either the actor in or the recipient of the stereotypical information is an outgroup member.

KEYWORDS communication, intergroup, language, linguistic expectancy bias, recipient effects, social context, stereotypes

DESPITE the fact that most stereotypes are socially shared and passed on from one person to another (see Haslam, 1997), until recently relatively little attention has been paid to the interpersonal aspects of stereotyping and the linguistic factors that mediate this process (see Hamilton, Gibbons, Stroessner, \& Sherman, 1992; Harasty, 1997; Haslam, 1997; Maass \& Arcuri, 1996). Although language plays an important role in most stereotyping research, this role is mostly confined to the content of national, ethnic, and racial stereotypes in the language of traits (e.g. Katz \& Braly, 1933; Park \& Judd, 1990), or the organizing function provided by traits in associative networks (e.g.

\section{Author's note}

Address correspondence to Daniël Wigboldus, Department of Social Psychology, Radboud University Nijmegen, PO BOX 9104, 6500 HE Nijmegen, The Netherlands [email: d.wigboldus@psych.ru.nl] 
Allport, 1954; Stangor \& Lange, 1994). Recently, however, several researchers have started investigating the interpersonal aspects of stereotyping (e.g. Lyons \& Kashima, 2003; Ruscher \& Lawson Duval, 1998; Schaller \& Conway, 1999). Moreover, as a result of the development of the linguistic category model (Semin \& Fiedler, 1988) specific linguistic mechanisms underlying the communication of stereotypes have been revealed (e.g. Douglas \& Sutton, 2003; Maass, Salvi, Arcuri, \& Semin, 1989; Wigboldus, Semin, \& Spears, 2000). In this research systematically biased language use is considered an influential interpersonal factor in the maintenance and transmission of stereotypes (for an overview, see Maass, 1999). In this article, the main focus is on the influence of the social communicative context on the production of such stereotypically biased language use. How does the social context evoked by the group membership of both the recipient of, and the actor in, a stereotype relevant message affect the use of biased language?

\section{Biased language use}

The linguistic category model (LCM: Semin \& Fiedler, 1988) distinguishes between four different levels of abstraction that correspond to four distinct word categories. Descriptive-action-verbs are the most concrete, and are used to convey a non-interpretive description of a single, observable event (e.g. 'A shakes B's hand'). Interpretive-action-verbs also describe a specific event, but are more abstract in that they refer to a general class of behaviors instead of a specific concrete behavior (e.g. 'A helps B'). State-verbs constitute the next category in degree of abstraction and describe an emotional state and not a specific event (e.g. 'A cares for B'). The most abstract predicates are adjectives (e.g. 'A is helpful'). These generalize across specific events and objects and describe only the subject (see for detail: Semin \& Fiedler, 1988). Although all of these examples may give an appropriate description of a specific event, the implicit meaning each description conveys varies systematically as a function of the level of abstraction of each description. For instance, relative to concrete descriptions such as action verbs, abstract descriptions such as traits give more information about the qualities of actors and less information about the qualities of the specific situation in which actors find themselves (Semin \& Fiedler, 1988, 1992). In this way the linguistic category model provides an interface between intra- and interpersonal social cognitive processes.

Based on the LCM, Anne Maass and colleagues (Maass et al., 1989) found evidence for a linguistic version of the intergroup bias phenomenon, the so called linguistic intergroup bias (LIB). This linguistic bias describes the finding that desirable ingroup behaviors and undesirable outgroup behaviors are described at a higher level of linguistic abstraction than undesirable ingroup behavior and desirable outgroup behavior. Especially in intergroup settings where the ingroup identity is threatened, support for this LIB pattern based on differences in social desirability has been found (Maass, Ceccarelli, \& Rudin, 1996; Maass et al., 1989). More recently, subsequent research has shown that the LIB can be considered as a specific example of a more general phenomenon. That is, in general, expectancy consistent behaviors are described at a higher level of linguistic abstraction than expectancy inconsistent behaviors (Maass, 1999; Maass, Milesi, Zabbini, \& Stahlberg, 1995; Wigboldus et al., 2000). This more general linguistic phenomenon has been labeled the linguistic expectancy bias or LEB (Maass, 1999; Wigboldus et al., 2000). Typically, it has been found that stereotype consistent information is described more abstractly than stereotype inconsistent information. For example, females behaving in a typical female way and males behaving typically male are described more abstractly (e.g. 'Lisa is careful' and 'Peter is decisive') than males behaving in a typical female way and females behaving typically male (e.g. 'Peter changes a diaper' or 'Lisa tells them what to do'; Wigboldus et al., 2000, Experiment 1). In the current article our main focus is on stereotypical expectancies and thus on the LEB.

Thus far, strong support for the occurrence of the LEB effect has been found in experimental 
as well as non-experimental studies, in a broad range of different intergroup contexts, in different languages, using closed ended (multiple choice), as well as open ended (free response) measures of linguistic abstraction (for an overview, see Maass, 1999). Importantly, it has also been shown that the biased linguistic pattern that results from the LEB mediates recipients' attributions in a stereotype confirming way (Wigboldus et al., 2000). Biased language use thus seems to play an important role in the transmission of stereotypical views.

\section{Communication, categorization, and stereotyping}

In most experiments performed so far on the LEB, participants were asked to describe a social event (e.g. Maass et al., 1995), or to transmit information about a social event to an anonymous other participant (e.g. Wigboldus et al., 2000). Surprisingly, the recipient of such communication until recently remained largely undefined. In everyday life it is very rare for a communicator to have no knowledge about the recipient(s). Even when communicating with a total stranger, information about a recipient's most relevant social category memberships such as gender, age, and origin, is mostly directly available from recipient's tone of voice, looks, or accent. Importantly, recipients' perceived characteristics have been shown to play a critical role in the communication process. That is, there is substantial evidence suggesting that communication is not merely the linear transmission of information from a transmitter to a recipient (e.g. Berlo, 1960) but, in addition, is strongly influenced by the context of the communication (for an overview, see Krauss \& Fussell, 1996). In particular the communicative context evoked by the recipient and the recipient's perceived characteristics have been shown to play an important role in this respect (e.g. Higgins, 1981; Kingsbury, 1968; Martijn, van der Pligt, \& Spears, 1996; McCann \& Higgins, 1992; Sedikides, 1990).

Recently, also with respect to the LIB and the LEB effect, it has been demonstrated that the occurrence of these biases may be moderated by the communicative context in general (i.e. what communication goals do communicators have? Douglas \& Sutton, 2003), and recipient characteristics in particular (Douglas \& McGarty, 2001, 2002; Fiedler, Bluemke, Friese, \& Hofmann, 2003; Gil de Montes, Semin, \& Valencia, 2003; Rubini \& Sigall, 2002; Semin, Gil de Montes, \& Valencia, 2003). For instance, with respect to the LIB, Gil de Montes et al. (2003) showed that the dependency of the relationship between a communicator and a recipient may moderate the LIB effect. In their research, communicators expected either to cooperate or to compete with a recipient. Subsequently, communicators were asked to describe a cartoon depicting either positive or negative behavior performed by an actor that was either liked (Experiment 1) or disliked (Experiment 2) by the recipient. When communicators expected to cooperate with recipients, they described positive behavior of a liked actor at a higher level of linguistic abstraction than negative behavior. When asked to describe an actor who was liked by a recipient that communicators expected to be competing with, negative behavior was described at a higher level of linguistic abstraction than positive behavior. For actors that were disliked by recipients, the reverse pattern of results was found. The dependency of the relationship between communicators thus affected the LIB effect.

The communicative context thus may moderate linguistic biases. The main focus in the current paper is on a specific element of the communicative context that, in our view, is especially relevant in the case of the transmission of stereotypes via the LEB, namely the social communicative context that is made up by the category membership of all parties involved. In an intragroup social communicative context the communicator and the recipient and the actor who is the topic of conversation all are members of the same group (i.e. a female communicator talking to a female recipient about a female actor). In an intergroup social communicative context one of the persons involved has a different group membership (i.e. a female communicator talking to a male recipient about a female 
target). A prerequisite for an LEB effect based on stereotypical expectancies to occur is of course the activation and subsequent linguistic application of a stereotype. On the basis of this stereotype, some behaviors of an actor will be interpreted as expectancy consistent and subsequently will be described more abstractly, while other behaviors will be interpreted as expectancy inconsistent and subsequently will be described more concretely. For example, the same aggressive behavior may be considered stereotype consistent when the actor is a skinhead, but stereotype inconsistent in the case of a little girl. Stereotype activation thus is crucial for the occurrence of an LEB effect based on stereotypes.

Importantly, the activation of specific stereotypes is dependent on social categorization processes. That is, stereotype activation requires category activation (see Higgins, 1989; van Knippenberg \& Dijksterhuis, 2000). The salience of categories at the moment an actor is described thus is of critical importance to stereotype activation and the LEB effect resulting from this activation. However, which categories are salient during a communicative act may be largely dependent on the social context. According to self-categorization theory (Oakes, 1987; Oakes, Haslam, \& Turner, 1994; Turner, Oakes, Haslam, \& McGarty, 1994) categorizing is inherently comparative and hence is intrinsically variable, fluid, and always context dependent. The salience of any given category will be a function of an interaction between its relative accessibility and the 'fit' between the category and reality.

In this article, we argue that the social category membership of a recipient and the actor described creates a social communicative context that renders certain social categorizations more accessible as a result of a high 'fit' between these categorizations and the reality provided by the social communicative context. In turn, this will reveal itself in an LEB effect based on the stereotypes that are part of the social categorization at hand. For example, when a female communicator communicates with a male recipient about a female actor, gender categorizations are likely to have a high fit and thus will be highly accessible, resulting in an LEB effect based on gender stereotypes. However, when a female transmitter communicates with a female recipient about a female actor, social categorization on the basis of gender differences has a relatively low fit and seems less relevant. After all, all parties involved are of the same gender, which renders social categorization on the basis of gender differences non-distinctive. Because stereotype activation requires category activation (see van Knippenberg \& Dijksterhuis, 2000), an LEB effect based on gender stereotypes should be attenuated in the latter case. In this way, the social communicative context evoked by the category memberships of the recipient, the actor described and the communicator may have a crucial influence on the occurrence of an LEB effect. When a specific social comparative context is made salient because either the actor or the recipient (or both) are from a distinctively different social category than the transmitter (intergroup social communicative context), this is likely to result in the increased activation of relevant stereotypes, which may be revealed by a significant LEB effect based on these stereotypes. However, when both the recipient and the actor are from the same social category as the transmitter (intragroup social communicative context), no specific social comparative context will be made salient, which will result in the absence of an LEB effect based on the stereotypes under consideration.

In the following sections, two studies are described that aimed to test the hypothesis that the LEB effect is stronger in an intergroup social communicative context than that in an intragroup social communicative context. In the first study, an open-ended research paradigm is used and gender groups form the basis for categorization. In the second study, a more controlled closed-ended research paradigm is used and two universities are used as a basis for categorization.

\section{Study 1}

To investigate the assumptions outlined above, an experiment was designed in which gender 
was used as a basis for categorization. Gender is a very salient ingroup versus outgroup variable in terms of which people categorize themselves and other people (Ashmore, 1981; Taylor, 1981). Another advantage of the use of genderstereotypes in the current experimental context is that most of them are shared by both men and women (Basow, 1992). Participants were asked to describe either a male or a female friend who engaged in typically female or typically male behavior. Importantly, the gender of the recipient of their communicative acts was known to participants. Social desirability of the behaviors was controlled for.

In line with the LEB phenomenon, we expected participants to communicate expectancy consistent behaviors (male actors performing typically male behaviors, female actors performing typically female behaviors) at a higher level of abstraction than expectancy inconsistent behaviors (male actors performing typically female behaviors, female actors performing typically male behaviors: Hypothesis 1). Moreover, we predicted that this LEB effect would be more pronounced in an intergroup social communicative context than in an intragroup social communicative context. We therefore expected the LEB described in Hypothesis 1 to be most evident when the recipient or the actor being described, or both, were outgroup members. When both the recipient and the actor being described were ingroup members, we expected the LEB to be less pronounced or even eliminated (Hypothesis 2).

\section{Method}

Participants A total of 66 Dutch undergraduate students (33 men and 33 women) from the Free University Amsterdam participated in this study $(M=21.79$ years old). Participants were recruited on campus and received Dfl. 10 (approximately US\$4) for their participation.

Design The study consisted of a 2 (participant gender: male vs. female) $\times 2$ (actor group membership: ingroup vs. outgroup) $\times 2$ (recipient group membership: ingroup vs. outgroup) $\times$ 2 (expectancy consistency: consistent vs. inconsistent) $\times 2$ (behavior desirability: desirable vs. undesirable) mixed design with repeated measures on the last two variables.

Procedure The experiment was run on computers and was described as a study on communication. The computer program randomly allocated each participant to one of the four between-participants cells of the design.

First, participants were asked to think of either a good male or a good female friend whom they knew well. On the basis of this manipulation actor group membership was defined as ingroup when the actor was of the same gender as the participant and as outgroup when the actor was not of the same gender as the participant. Then participants had to give some background information about this friend. After this the actual experiment began. Participants were asked to communicate four true stories about their friend. In each story, one specific behavioral event had to be described that participants had witnessed their friend engage in. We asked participants to communicate one story in which their friend demonstrated desirable, typically male behavior; one story in which their friend demonstrated desirable, typically female behavior; one in which the actor showed undesirable, typically male behavior; and one in which the actor showed undesirable, typically female behavior. The typically male behaviors served as expectancy consistent behaviors for male actors and expectancy inconsistent behaviors for female actors. For the typically female behaviors the reverse was the case. The order of the stories was randomized. Participants could communicate their stories by typing them into the computer. Before writing the stories, they were told that later on in the experiment they would have to read their typed messages out loud to another participant. It was made clear whether this recipient was a male or a female person. Recipient group membership thus was defined as ingroup when the recipient was of the same gender as the participant, and outgroup when the recipient was not of the same gender as the participant. When a participant had finished writing the four stories he or she was informed that it was 
not necessary to read the stories aloud to another participant.

In order to check our manipulations, we asked participants to change computers with another participant (whom they did not see) and read and judge the four stories this other participant had written on the computer. This way, each participant judged the stories of one unknown other participant. The four stories were presented in random order and each story was followed by two questions that served as manipulation checks for the expectancy consistency manipulation. For each story separately, participants were asked to indicate on a 7-point scale, ranging from not at all (1) to very much (7) to what extent they considered the behavior displayed in the story to be: (1) typically male; (2) typically female.

Finally, participants indicated their age, were debriefed, and thanked for their participation in the experiment.

Dependent variable The dependent variable consisted of the abstraction level of the stories participants wrote. The information each participant transmitted was coded by an independent rater familiar with Semin and Fiedler's (1988, 1991) Linguistic Category Model and its scoring criteria. First, every verb (interpersonal as well as non-interpersonal) and every adjective referring to the actor of the story was coded according to the LCM. The four categories were then scored in the following way: Descriptive Action Verbs $=1$; Interpretive Action Verbs $=2$; State verbs $=3$; Adjectives $=4$ (Semin \& Fiedler, 1989). On the basis of these scores the mean level of abstraction was computed for each story separately by adding the different scores and dividing them by their number. The mean level of abstraction for each story could thus vary between 1 (only DAVs, very concrete) and 4 (only ADJs, very abstract). Half of the 264 stories (randomly chosen) was also coded by a second rater to test the consistency of the coding, which was satisfactory $($ Cohen's kappa $=.70)$.

\section{Results}

Manipulation check In order to check our expectancy consistency manipulation, the extent to which participants' stories described typically male behavior or typically female behavior was rated by another participant. On the basis of these ratings we calculated a mean typicality rating for expectancy consistent storyrating combinations (typically male rating for typically male story, typically female rating for typically female story) and expectancy inconsistent combinations (typically male rating for typically female story, typically female rating for typically male story). These ratings were subjected to a 2 (participant gender: male vs. female) $\times 2$ (actor group membership: ingroup vs. outgroup) $\times 2$ (recipient group membership: ingroup vs. outgroup) $\times 2$ (expectancy consistency: consistent vs. inconsistent) $\times 2$ (behavior desirability: desirable vs. undesirable) mixed design with repeated measures on the last two variables. Three cases were omitted from these analyses because of missing values. The writers of these stories did not want another participant to read and judge their stories. Of course their wish was granted. A reliable main effect for expectancy consistency confirmed our expectancy consistency manipulation $(F(1,55)$ $\left.=122.13, p<.01, \eta^{2}=.66\right)$. Expectancy consistent story-rating combinations were rated as more typical $(M=4.78)$ than expectancy inconsistent combinations $(M=3.06)$. In addition, we found two smaller, but reliable effects; namely a significant main effect for behavior desirability $\left(F(1,55)=6.25, p=.02, \eta^{2}=.09\right)$; and an interaction between behavior desirability and participant gender $(F(1,55)=7.98, p<.01$, $\left.\eta^{2}=.11\right)$. No other effects were found. Importantly, expectancy consistency thus was not moderated by any of the other variables.

Mean level of abstraction Abstraction level was subjected to a 2 (participant gender: male vs. female) $\times 2$ (actor group membership: ingroup vs. outgroup) $\times 2$ (recipient group membership: ingroup vs. outgroup) $\times 2$ (expectancy consistency: consistent vs. inconsistent) $\times 2$ (behavior desirability: desirable vs. undesirable) mixed design with repeated measures on the last two variables. No effects were found involving participant gender. These non-effects justify the transformations described 
above, in which we collapsed participant gender and actor gender into actor group membership, and participant gender and recipient gender into recipient group membership.

In line with Hypothesis 1, a marginally significant main effect for expectancy consistency was obtained $\left(F(1,58)=3.20, p=.08, \eta^{2}=.04\right)$. In general, and in line with the LEB phenomenon, expectancy consistent information $(M=$ 2.25) was communicated at a somewhat higher level of linguistic abstraction than expectancy inconsistent information $(M=2.13)$. Importantly, and in line with Hypothesis 2, this expectancy effect was moderated by the communicative context made up by the group membership of the actor and the recipient. That is, a significant three-way interaction was found between expectancy consistency, actor group membership, and recipient group membership $\left(F(1,58)=5.78, p=.02, \eta^{2}=.07\right)$ (see Table 1). We predicted a significant LEB effect for expectancy consistency in all intergroup social communicative context conditions. In line with this prediction, simple effects revealed that the LEB main effect for expectancy consistency was reliable when both the actor and the recipient were outgroup members $(F(1,58)=$ $\left.3.26, p=.04, \eta^{2}=.05\right)$; when the actor was an outgroup member and the recipient an ingroup member $(F(1,58)=3.93, p=.03$, $\left.\eta^{2}=.06\right)$; and when the actor was an ingroup member and the recipient an outgroup

Table 1. Mean level of abstraction as a function of actor group membership, recipient group membership, and expectancy consistency

Expectancy consistency

\begin{tabular}{lcc} 
Actor group membership & Consistent & Inconsistent \\
\hline Recipient ingroup & & \\
Ingroup $(n=12)$ & 1.99 & $2.24^{*}$ \\
Outgroup $(n=20)$ & 2.35 & $2.16^{*}$ \\
Recipient outgroup & & \\
Ingroup $(n=18)$ & 2.36 & $2.11^{* *}$ \\
Outgroup $(n=16)$ & 2.21 & $2.02^{*}$ \\
\hline
\end{tabular}

Notes: $N=66$. Values can vary between 1 and 4 with higher values indicating higher levels of abstraction. Cell means in rows differ at $* p<.05 ; * * p<.01$. member $\left(F(1,58)=6.56, p<.01, \eta^{2}=.10\right)$. However, in the intragroup social communicative context condition in which both the actor and the recipient were ingroup members, a significant reversal of the LEB effect was found. That is, expectancy inconsistent information was described at a higher level of linguistic abstraction than expectancy consistent information $\left(F(1,58)=4.25, p=.02, \eta^{2}=.07\right)$.

Besides these hypothesized effects, the analysis revealed a significant main effect for behavior desirability $(F(1,58)=5.89, p=.02$, $\left.\eta^{2}=.09\right)$, indicating that desirable behaviors were communicated more abstractly $(M=2.28)$ than undesirable behaviors $(M=2.10)$. Also an interaction between expectancy consistency and recipient group membership was found $\left(F(1,58)=5.93, p=.02, \eta^{2}=.07\right)$. This effect was modified by the higher order interaction described above. No other effects were found.

\section{Discussion}

The present experiment delivers evidence that the production of an LEB effect is not inevitable and may be influenced by the social communicative context. In line with the notion that the stereotype activation that underlies an LEB effect requires category activation (van Knippenberg \& Dijksterhuis, 2000), and the assumption that category activation depends on the fit (Oakes, 1987) between a specific categorization and the social communicative social context, a significant LEB effect was found only when gender differed across the parties involved in a communicative act. No evidence for an LEB effect was found when gender did not vary across the parties involved.

Interestingly, in the intragroup social communicative context participants not only showed a reduced LEB effect, they actually demonstrated the reverse pattern to the LEB. That is, the expectancy inconsistent information was communicated at a higher level of abstraction than the expectancy consistent information. This reversal seems to run counter to the notion that the LEB is a general phenomenon that applies to groups as well as to individuals (Maass et al., 1995). However, it could be argued that when people do not 
categorize themselves and others on the basis of a salient group membership but as individuals, expectancy inconsistent information is more informative, diagnostic, and more salient than expectancy consistent information (Fiske \& Neuberg, 1990; Jones \& Davis, 1965; Stangor \& McMillan, 1992). Expectancy inconsistent information thus may be communicated at a higher level of abstraction when people describe others at a more individual level, which might have been the case in the current intragroup context.

However, at least some form of category activation must have been present for the information to be considered as expectancy consistent or expectancy inconsistent. This may have been due to the fact that we asked participants to come up with their own behavioral examples and asked them to describe a friend engaging in typically male and typically female behavior. The sheer asking for typically male and typically female behavioral examples, at least to some extent, may have activated gender based expectancies. Possibly, these expectancies have resulted in an inverse LEB effect in the intragroup social communicative context condition.

One of the strong points of the present study is that transmitters generated their own behavioral examples and communicated them in their own words. Most research performed so far on the LEB utilized a fixed response format in which participants were asked to choose between (e.g. Maass et al., 1995), or rate (von Hippel, Sekaquaptewa, \& Vargas, 1997) fixed descriptions that differed in their level of linguistic abstraction. The current finding that an LEB pattern emerges when transmitters use their own words to describe events based on their own personal experience strongly adds to the validity of this bias. However, the free response format of the current experiment also leads to a less controlled experiment. The stories participants generated varied not only in terms of language abstraction but also on an innumerable number of other variables (i.e. number of words, content, grammatical mistakes, and so on).

In order to test the reliability of the effects found in Study 1 using a more controlled research method, we performed a second study in which we used a fixed response format. Because, in Study 2, participants were presented with existing behavioral information, the typicality of the behaviors did not need to be stated explicitly. As a basis for categorization, two different universities were used. Recipient category membership was manipulated by informing participants that the research they participated in was conducted by researchers from either the one or the other university.

\section{Study 2}

Amsterdam has two universities. The University of Amsterdam (Universiteit van Amsterdam, UvA) and the Free University (Vrije Universiteit, VU). As is mostly the case whenever people are divided into groups, there are clear stereotypical views attached to students of both universities (Doff, 1998). For example, students of the UvA are known to be independent spirits but also sloppy ones whereas students of the $\mathrm{VU}$ are seen as serious and hard working but also a bit boring. In the present study, these two universities were used as a basis for categorization. Four stories were created describing an actor engaging in typically UvA and typically VU behavior. Again, social desirability of the behaviors was controlled for. Participants, all students from the UvA, were asked to read the stories, and on the basis of each story separately rate the appropriateness of four descriptor sentences differing in language abstraction that were given underneath the stories. Importantly, the actors described were either four different students from the UvA or four different students from the VU. As noted above, recipient category membership was manipulated by stating on the front page of the questionnaire that the research was conducted and would be analyzed by social psychology researchers from either the UvA or the VU.

In line with the LEB phenomenon and the results of Study 1, we expected participants to rate more abstract descriptors as more appropriate for stories describing expectancy consistent behaviors (UvA student engaging in typically UvA behaviors, VU students engaging in typically VU behaviors) than for stories 
describing expectancy inconsistent behaviors (UvA student engaging in typically VU behaviors, VU students engaging in typically UvA behaviors; Hypothesis 1). Moreover, we predicted that this LEB effect would be more pronounced in an intergroup social communicative context than in an intragroup social communicative context. We therefore expected the LEB described in Hypothesis 1 to be most evident when the recipient, the actor being described, or both are outgroup members (VU related). When both the recipient and the actor being described are ingroup members (UvA related), we expected the LEB to be less pronounced or even eliminated (Hypothesis 2).

\section{Method}

Participants A total of 222 Dutch undergraduate psychology students (46 men and 176 women) from the University of Amsterdam participated in this study in order to partially fulfill course requirements $(M=22.14$ years old $)$.

Design The study consisted of a 2 (actor group membership: ingroup vs. outgroup) $\times 2$ (recipient group membership: ingroup vs. outgroup) $\times 2$ (expectancy consistency: consistent vs. inconsistent) $\times 2$ (behavior desirability: desirable vs. undesirable) mixed design with repeated measures on the last two variables.

Materials Expectancy consistency and behavior desirability were manipulated by presenting participants with four different scenarios containing socially desirable and undesirable behaviors performed by four different actors (two male names and two female names were used). Two scenarios described actions that may be considered stereotypical for students of the VU (desirable: making a summary right after a lecture; undesirable: staying home reading a book instead of going to a party to which you are invited). Similarly, two scenarios described actions that may be considered stereotypical for students of the UvA (desirable: calling companies for a student internship of your own accord; undesirable: not showing up for an oral exam). These behaviors were based on traits that have been shown
(Doff, 1998) to be stereotypical for VU students (seen as serious and hard working but also a bit boring) and counterstereotypical for UvA students, and traits that are stereotypical for UvA students (seen as independent but also a bit sloppy) and counterstereotypical for VU students. Typically UvA behaviors performed by UvA actors and typically VU behaviors performed by VU actors thus were expectancy consistent whereas typically UvA behaviors performed by VU actors and typically VU behaviors performed by UvA actors can be considered as expectancy inconsistent (Doff, 1998).

Each scenario consisted of two to three sentences describing an actor engaging in a particular action. Below each scenario four sentences were presented corresponding to the four levels of linguistic abstraction described by the LCM (Semin \& Fiedler, 1988). For example, the following is the scenario describing desirable, typical UvA behavior, and the accompanying descriptor sentences:

Karin, a 23-year-old student at the University of Amsterdam wants to obtain some work experience via a student internship. Her supervisor at the University has some places available. However, instead of waiting for places offered to her by her supervisor, she phones the companies she would like to work for, on her own initiative.

Karin phones companies all day.

Karin arranges her own student internship.

Karin likes to arrange her own things.

Karin is an independent student.

For each descriptor sentence separately, participants were asked to rate on a 7-point scale, ranging from not at all (1) to very much (7) to what extent this sentence was applicable to the scenario.

Procedure The experiment was part of a test battery in which participants filled out several questionnaires. The present experiment was presented as a questionnaire on person descriptions. On the first page of the questionnaire, recipient group membership was manipulated by informing participants that 
this research was performed by researchers of the social psychology department of either the UvA (ingroup) or the VU (outgroup). On the second page of the questionnaire, actor group membership was manipulated by informing participants that they would be presented with four short stories about four students that all came from either the UvA (ingroup) or the VU (outgroup). Moreover, at the beginning of each story, the actor was continually introduced as a student of either the UvA or the VU. Participants were randomly assigned to each of these four experimental between-participants conditions.

Subsequently, participants were presented with the four scenarios described earlier and rated the accompanying descriptor sentences.

Finally, participants were asked to indicate on 7-point scales, ranging from not at all (1) to very much (7) to what extent each of the typically UvA (independent, sloppy) and typically VU traits (serious, boring) applied to the average UvA student and the average VU student. With these measures we aimed to check our expectancy consistency manipulation.

Dependent variable The dependent variable consisted of the ratings participants made for each scenario on the basis of the four descriptors corresponding to the four levels of linguistic abstraction described by the LCM (Semin \& Fiedler, 1988). In line with the LCM and the scoring of the open ended data in Study 1, the four descriptors were weighted in the following way: Descriptive Action Verb $=1$; Interpretive Action Verb $=2$; State verb $=3$; Adjective $=4$ (Semin \& Fiedler, 1989). Moreover participants' ratings were recoded by subtracting 1 from each rating, so that ratings ranged from 0 to 6 . On the basis of the descriptor weights and participants' ratings $\left(\mathrm{r}_{\mathrm{DAV}}, \mathrm{r}_{\mathrm{IAV}}, \mathrm{r}_{\mathrm{SV}}\right.$, and $\left.\mathrm{r}_{\mathrm{ADJ}}\right)$ the mean abstraction rating (MAR) for each scenario was computed in the following way:

$$
M A R=\frac{\begin{array}{l}
\left(r_{D A V} \times 1\right)+\left(r_{I A V} \times 2\right)+ \\
\left(r_{S V} \times 3\right)+\left(r_{A D J} \times 4\right)
\end{array}}{\left(r_{D A V}+r_{I A V}+r_{S V}+r_{A D J}\right)}
$$

The mean abstraction rating for each story could thus vary between 1 (only DAV descriptor rated as applicable, very concrete) and 4 (only ADJ descriptor rated as applicable, very abstract). ${ }^{1}$

\section{Results}

Manipulation check In order to check our expectancy consistency manipulation, participants were asked to indicate to what extent each of the typically UvA and typically VU traits applied to the average UvA student and the average VU student. On the basis of these ratings we calculated a mean typicality rating for expectancy consistent combinations (UvA traits applied to UvA students, VU traits applied to VU students) and expectancy inconsistent combinations (UvA traits applied to VU students, VU traits applied to UvA students). These applicability ratings were subjected to a 2 (actor group membership: ingroup vs. outgroup) $\times 2$ (recipient group membership: ingroup vs. outgroup) $\times 2$ (expectancy consistency: consistent vs. inconsistent) $\times 2$ (group rated: UvA vs. VU) mixed analysis of variance (ANOVA) with repeated measures on the last two variables. A reliable main effect for expectancy consistency confirmed our expectancy consistency manipulation $(F(1$, $\left.218)=101.98, p<.01, \eta^{2}=.31\right)$. For expectancy consistent university-trait combinations, traits were rated as more applicable $(M=4.32)$ than for expectancy inconsistent combinations $(M=$ 3.76). These results confirm our expectancy consistency manipulation. The applicability ANOVA also revealed a main effect for group rated $\left(F(1,218)=15.56, p=.04, \eta^{2}=.07\right)$. In general, traits were rated as more applicable to the average VU student $(M=4.11)$ than to the average UvA student $(M=3.97)$. Also, a two-way interaction was found between expectancy consistency and group rated $(F(1,218)=4.24$, $\left.p=.04, \eta^{2}=.02\right)$. Simple effects revealed that the expected simple main effect for expectancy was somewhat stronger for the ratings of the VU group $\left(F(1,218)=28.71, p<.01, \eta^{2}=.12\right)$; than for the ratings of the UvA group $(F(1,218)=$ $\left.80.25, p<.01, \eta^{2}=.27\right)$. Importantly, however, in both cases the expectancy simple main effect 
was reliable. Finally, a three-way interaction was found between expectancy consistency, recipient group membership, and actor group membership $\left(F(1,218)=4.22, p<.05, \eta^{2}=.01\right)$. Again, simple effects revealed that the expected simple main effect for expectancy consistency was reliable in all four communicative context conditions (all $p \mathrm{~s}<.01, \eta^{2}$ varied between .05 and .18). No other effects were found. In sum, although the reliability of the expectancy manipulation differed somewhat between conditions, expectancy consistency was successfully manipulated in all conditions.

Mean abstraction rating Mean abstraction ratings were subjected to a 2 (actor group membership: ingroup vs. outgroup) $\times 2$ (recipient group membership: ingroup vs. outgroup) $\times 2$ (expectancy consistency: consistent vs. inconsistent) $\times 2$ (behavior desirability: desirable vs. undesirable) mixed ANOVA with repeated measures on the last two variables. In line with Hypothesis 1, a reliable main effect for expectancy consistency was found $(F(1,218)=$ 44.62, $\left.p<.01, \eta^{2}=.16\right)$. In line with the LEB phenomenon, expectancy consistent scenarios received relatively more abstract ratings $(M=$ 2.38) than expectancy inconsistent scenarios $(M=2.29)$. Importantly, this effect was moderated by recipient group membership and actor

Table 2. Mean level of abstraction as a function of actor group membership, recipient group membership, and expectancy consistency

\begin{tabular}{lcc}
\hline & \multicolumn{2}{c}{ Expectancy consistency } \\
\cline { 2 - 3 } Actor group membership & Consistent & Inconsistent \\
\hline Recipient UvA & & \\
UvA $(n=59)$ & 2.37 & 2.38 \\
VU $(n=51)$ & 2.36 & $2.22 * *$ \\
Recipient VU & & \\
UvA $(n=59)$ & 2.42 & $2.29 * *$ \\
VU $(n=53)$ & 2.37 & $2.28 * *$ \\
\hline
\end{tabular}

Notes: $N=222$. Participants were students of the University of Amsterdam (UvA). The Free University Amsterdam (VU) is the other university in Amsterdam. Values can vary between 1 and 4 with higher values indicating higher abstraction ratings. Cell means in rows differ at $* * p<.01$. group membership. That is, a significant threeway interaction was found between expectancy consistency, recipient group membership and actor group membership $(F(1,218)=11.59$, $\left.p<.01, \eta^{2}=.04\right)$ (see Table 2 ). We predicted a significant LEB effect for expectancy consistency in all intergroup social communicative context conditions. In line with this prediction, simple effects revealed that the LEB main effect for expectancy consistency was reliable when both the actor and the recipient were outgroup members $\left(F(1,218)=12.80, p<.01, \eta^{2}=.06\right)$; when the actor was an outgroup member and the recipient an ingroup member $(F(1,218)=$ $\left.24.29, p<.01, \eta^{2}=.10\right)$; and when the actor was an ingroup member and the recipient an outgroup member $(F(1,218)=26.20, p<.01$, $\left.\eta^{2}=.11\right)$. However, in the intragroup social communicative context condition in which both the actor and the recipient were ingroup members, no reliable simple main effect for expectancy consistency was found $(F(1,218)=$ $\left.0.15, p=.70, \eta^{2}=.00\right)$. Thus, again no evidence for the LEB was found in an intragroup communicative context.

Besides these hypothesized effects, a main effect for behavior desirability was found $(F(1$, $\left.218)=352.17, p<.01, \eta^{2}=.61\right)$, indicating that desirable scenarios $(M=2.51)$ were rated more abstractly than undesirable scenarios $(M=$ 2.17). Also, an interaction between expectancy consistency and behavior desirability $(F(1,218)$ $=86.65, p<.01 \eta^{2}=.28$ ) was found, indicating that expectancy inconsistent undesirable behaviors were rated at a lower level of abstraction than the other types of behaviors (for all specific comparisons, $p<.01)$. Additional effects are not discussed as they were modified by higher order interactions. These were an interaction between actor group membership and expectancy consistency $(F(1,218)=4.43$, $\left.p=.04, \eta^{2}=.02\right)$; and a main effect for actor group membership $(F(1,218)=5.23, p=.02$, $\left.\eta^{2}=.02\right)$. No other effects were found.

\section{Discussion}

The present experiment delivers further evidence for the idea that the production of an LEB effect may be influenced by the 
communicative social context. Importantly, in the current experiment, the social context (universities) as well as the research method (closed ended ratings) differed from Study 1. Despite these differences, the effects found in Study 2 were comparable to those found in Study 1. Again, evidence for the occurrence of an LEB effect was found in an intergroup social communicative context but not in an intragroup social communicative context.

Study 2 overcame one of the methodological problems of Study 1, namely that in the intragroup social communicative context participants were asked to generate typically male and female stories. As a result, in Study 1, at least some form of category activation may have been present in the intragroup condition which may have led to the reversal of the LEB effect. In the Study 1 intragroup condition, expectancy inconsistent information may have been more informative, diagnostic, and more salient, resulting in more abstract language use. In Study 2, participants were simply confronted with behaviors, without mentioning their typicality. As a result the UvA-VU comparison was not activated at all in the intragroup condition in Study 2. Participants thus could not have known what was to be expected of each actor. This difference between Study 1 and Study 2 may account for the finding that in the intragroup condition in Study 2, the LEB reversal found in Study 1 was not present.

\section{General discussion}

Research on the LEB (Maass, 1999; Wigboldus et al., 2000) has shown that there are subtle and systematic differences in the linguistic representation of social events as a function of stereotypical views. That is, in general, stereotype consistent information is communicated at a higher level of linguistic abstraction than stereotype inconsistent information. The main goal of the present work was to investigate the influence of a recipient's category membership on the production of an LEB effect. Two experiments were performed which aimed to test the influence of the social communicative context elicited by the group membership of the recipient and the actor being described on the production of an LEB effect. Both experiments supported the assumption that the production of an LEB effect is moderated by this social communicative context. In both studies, participants produced an LEB effect whenever the actor, the recipient, or both were from a different social category than the communicator. However, when both the actor and the recipient were of the same social category, a reversed LEB effect (Study 1) or no LEB effect (Study 2) was produced.

With this, both experiments supported our predictions that were based on two assumptions. First, it was assumed that the activation of specific stereotypes is dependent on social categorization processes. That is, stereotype activation requires category activation (see van Knippenberg \& Dijksterhuis, 2000). Second, it was assumed that the salience of a category depends on the fit between this categorization and the social context (e.g. Oakes, 1987). On the basis of these two assumptions, we argued that when a specific social comparative context is made salient because the actor or the recipient (or both) are from a distinctively different social category than the transmitter (intergroup social communicative context), this will result in the increased activation of relevant stereotypes, which reveals itself in an LEB effect. However, when both the recipient and the actor are from the same social category as the transmitter (intragroup social communicative context), no specific social comparative context will be made salient, which will result in the absence of an LEB effect. The LEB results of both Study 1 and Study 2 supported this line of reasoning.

It should be noted that the current experiments do not deliver clear cut proof for the assumed underlying self categorization mechanism. Although the results are very much in line with a social categorization account, there was no check on the intragroup/intergroup identity salience and the resulting stereotype activation of participants in the different conditions. Future research may incorporate such measures, and these should mediate the effect of the social communicative context on the 
LEB found in the current studies. Without identity salience and stereotype activation checks, alternative explanations for the current pattern of results remain possible. For instance, within Haviland and Clark's (1974) given-new contract framework, in the intragroup social context condition, the given could be taken for granted because this is shared with the other ingroup members and thus the emphasis of the communication task will be on the new information. This may be done by using relatively more abstract terms for what is new. In the intergroup context, a stronger emphasis may be put on the given in order to be able to establish common ground with the recipient in the intergroup context. This may be achieved by using relatively more abstract language for what is given. ${ }^{2}$ Hopefully, future research will reveal more about the processes underlying the current findings.

Nevertheless, some interesting implications may be derived from the current results. First and most importantly, the current studies seem to provide convincing evidence for the notion that the characteristics of a recipient may influence the production of a linguistic bias when stereotype-relevant information gets communicated from one person to another. In line with earlier research indicating the importance of recipients' characteristics for the communication process (e.g. Higgins, 1981; Kingsbury, 1968; Krauss \& Fussell, 1996; McCann \& Higgins, 1992), the current findings indicate that the interpersonal transmission of stereotypes by means of a linguistic bias may be strongly influenced by the characteristics of a recipient. It may therefore be important for future LEB research to take the relevant recipient characteristics into account when studying the production of a linguistic bias (see Fiedler et al., 2003).

Second, the current findings demonstrate that the LEB effect does not operate unconditionally whenever people are asked to describe stereotype-relevant behaviors, but instead is context dependent. In line with other recent research on the specific conditions under which linguistic abstraction biases occur (Douglas \& Sutton, 2003; Fiedler et al., 2003;
Gil de Montes et al., 2003; Semin et al., 2003), the current results indicate that it is possible to obstruct the production of an LEB effect based on stereotypical views. The findings from both our studies clearly indicate that the production of an LEB effect based on stereotypes is absent when there is no salient relevant intergroup context. Future research will have to provide more insight into the conditions under which people do and do not produce an LEB effect. Interestingly, recent research by Semin et al. (2003) has demonstrated that whereas LIB effects were observed when transmitters were asked to send a message to a recipient, in a control condition where the messages had no communicative function, no effects were observed. Presumably, not only the relationship between a transmitter and a recipient is of importance to the construction of a message, but also whether the message has a communicative function. Future research is necessary to reveal more about the communicative prerequisites for an LEB effect to occur.

At a more theoretical level, an intriguing implication of the current research is the idea that the social communicative context evoked by the social category membership of a recipient may influence the communication of stereotypes at an interpersonal level. As argued before by others (Doosje, Haslam, Spears, Oakes, \& Koomen, 1998; Ellemers \& van Knippenberg, 1997; Oakes et al., 1994; Spears, Oakes, Ellemers, \& Haslam, 1997) stereotypes and group perceptions should not be seen as fixed 'pictures in our heads' (Lippmann, 1922) but as dependent on relevant aspects of the social context and the perspective of the perceiver. In everyday life, the characteristics of the people we communicate with constitute an important part of this social context. The research presented in this article demonstrates that contextual aspects such as these may even get reflected in the linguistic tools people use to communicate with others. Not only the way we perceive social reality is dependent on relevant aspects of the social context, but also the way in which we communicate this social reality to others. In this way, stereotypes are maintained not only within individuals but also between individuals. 


\section{Notes}

1. None of the participants rated each of the four descriptors of a scenario as 'not at all' applicable. Therefore, there were no divisions by zero. Note that in calculating the mean abstraction rating in this way, an abstraction score comparable to the mean level of linguistic abstraction used in Study 1 is obtained. Not only does the mean abstraction rating result also in a score between 1 and 4, it also behaves in a similar way. For example, when only the DAV rating is above zero, it does not matter for the mean abstraction rating how high this rating is, the mean abstraction rating will always be 1 . Likewise, when only DAVs are used to describe a scene in your own words, the mean level of abstraction also will be 1 , independent of the number of DAVs used.

2. We would like to thank Klaus Fiedler for pointing out this alternative explanation.

\section{Acknowledgments}

This research was supported by the Netherlands Organization for Scientific Research (Grants PPS 98-031 and PGS 56-381). We thank Gooitske Marsman and Sandra Zwier for assistance in coding the data of Study 1.

\section{References}

Allport, G. (1954). The nature of prejudice. Reading, MA: Addison-Wesley.

Ashmore, R. D. (1981). Sex stereotypes and implicit personality theory. In D. Hamilton (Ed.), Cognitive processes in stereotyping and intergroup behavior (pp. 37-81). Hillsdale, NJ: Erlbaum.

Basow, S. A. (1992). Gender stereotypes and roles (3rd ed.). Belmont, CA: Brooks/Cole.

Berlo, D. K. (1960). The process of communication: An introduction to theory and practice. New York: Holt, Rinehart, \& Winston.

Doff, T. (1998). Is verdediging de beste aanval? (Is defense the best attack?) Unpublished Master's thesis, University of Amsterdam.

Doosje, B., Haslam, S. A., Spears, R., Oakes, P. J., \& Koomen, W. (1998). The effect of comparative context on central tendency and variability judgements and the evaluation of group characteristics. European Journal of Social Psychology, 28, 173-184.

Douglas, K. M., \& McGarty, C. (2001). Identifiability and self-presentation: Computer-mediated communication and intergroup interaction. British Journal of Social Psychology, 40, 399-416.

Douglas, K. M., \& McGarty, C. (2002). On computers and elsewhere: A model of the effects of Internet identifiability on communicative behavior. Group Dynamics: Theory, Research and Practice, 6, 17-26.

Douglas, K. M., \& Sutton, R. M. (2003). Effects of communication goals and expectancies on language abstraction. Journal of Personality and Social Psychology, 84, 682-696.

Ellemers, N., \& van Knippenberg, A. (1997). Stereotyping in social context. In R. Spears, P. J. Oakes, N. Ellemers, \& S. A. Haslam (Eds.), The social psychology of stereotyping and group life (pp. 119-143). Oxford, UK: Blackwell.

Fiedler, K., Bluemke, M., Friese, M., \& Hofmann, W. (2003). On the different uses of linguistic abstractness: From LIB to LEB and beyond. European Journal of Social Psychology, 33, 441-453.

Fiske, S. T., \& Neuberg, S. L. (1990). A continuum of impression formation, from category-based to individuating processes: Influences of information and motivation on attention and interpretation. In M. P. Zanna (Ed.), Advances in experimental social psychology (Vol. 23, pp. 1-74). San Diego, CA: Academic Press.

Gil de Montes, L., Semin, G. R., \& Valencia, J. F. (2003). Communication patterns in interdependent relationships. Journal of Language and Social Psychology, 22, 259-281.

Hamilton, D. L., Gibbons, P. A., Stroessner, S. J., \& Sherman, J. W. (1992). Language, intergroup relations and stereotypes. In G. R. Semin \& K Fiedler (Eds.), Language, interaction and social cognition (pp. 102-128). London: Sage.

Harasty, A. S. (1997). The interpersonal nature of social stereotypes: Differential discussion patterns about ingroups and outgroups. Personality and Social Psychology Bulletin, 23, 270-284.

Haslam, S. A. (1997). Stereotyping and social influence: Foundations of stereotype consensus. In R. Spears, P. J. Oakes, N. Ellemers, \& S. A. Haslam (Eds.), The social psychology of stereotyping and group life (pp. 119-143). Oxford, UK: Blackwell.

Haviland, S. E., \& Clark, H. H. (1974). What's new? Acquiring new information as a process in comprehension. Journal of Verbal Learning and Verbal Behavior, 13, 512-521.

Higgins, E. T. (1981). The 'communication game': Implications for social cognition and persuasion. In E. Higgins, M. Zanna, \& C. Herman (Eds.), Social cognition: The Ontario symposium (Vol. 1, pp. 343-392). Hillsdale, NJ: Erlbaum.

Higgins, E. T. (1989). Knowledge accessibility and 
activation: Subjectivity and suffering from unconscious sources. In J. S. Uleman \& J. A. Bargh (Eds.), Unintended thought (pp. 75-123). New York: Guilford.

Jones, E. E., \& Davis, K. E. (1965). From acts to dispositions: The attribution process in person perception. In L. Berkowitz (Ed.), Advances in experimental social psychology (Vol. 2, pp. 219-266). New York: Academic Press.

Katz, D., \& Braly, K. (1933). Racial stereotypes in one hundred college students. Journal of Abnormal and Social Psychology, 28, 280-290.

Kingsbury, D. (1968). Manipulating the amount of information obtained from a person giving directions. Unpublished honors thesis, Harvard University, Department of Social Relations, Cambridge, MA.

Krauss, R. M., \& Fussell, S. R. (1996). Social psychological models of interpersonal communication. In E. T. Higgins \& A. W. Kruglanski (Eds.), Social psychology: Handbook of basic principles (pp. 655-701). New York: Guilford.

Lippmann, W. (1922). Public opinion. New York: Harcourt Brace.

Lyons, A., \& Kashima, Y. (2003). How are stereotypes maintained through communication? The influence of stereotype sharedness. Journal of Personality and Social Psychology, 85, 989-1005.

Maass, A. (1999). Linguistic intergroup bias: Stereotype perpetuation through language. In M. P. Zanna (Ed.), Advances in experimental social psychology (Vol. 31, pp. 79-121). San Diego, CA: Academic Press.

Maass, A., \& Arcuri, L. (1996). Language and stereotyping. In N. Macrae, C. Stangor, \& M. Hewstone (Eds.), Stereotypes and stereotyping (pp. 193-226). New York: Guilford.

Maass, A., Ceccarelli, R., \& Rudin, S. (1996). Linguistic intergroup bias: Evidence for ingroup-protective motivation. Journal of Personality and Social Psychology, 71, 512-526.

Maass, A., Milesi, A., Zabbini, S., \& Stahlberg, D. (1995). Linguistic intergroup bias: Differential expectancies or ingroup protection? Journal of Personality and Social Psychology, 68, 116-126.

Maass, A., Salvi, D., Arcuri, L., \& Semin, G. (1989). Language use in intergroup contexts: The linguistic intergroup bias. Journal of Personality and Social Psychology, 57, 981-993.

Martijn, C., van der Pligt, J., \& Spears, R. (1996). Judging attitudes: Description, evaluation and type of implication of judgmental language. Social Cognition, 14, 77-91.

McCann, C. D., \& Higgins, E. T. (1992). Personal and contextual factors in communication:
A review of the 'communication game'. In G. Semin \& K. Fiedler (Eds.), Language, interaction and social cognition (pp. 144-172). Newbury Park, CA: Sage.

Oakes, P. J. (1987). The salience of social categories. In J. C. Turner, M. A. Hogg, P. J. Oakes, S. D. Reicher, \& M. S. Wetherell (Eds.), Rediscovering the social group: A self-categorization theory (pp. 117-141). Oxford, UK: Basil Blackwell.

Oakes, P. J., Haslam, S. A., \& Turner, J. C. (1994). Stereotyping and social reality. Oxford, UK: Blackwell.

Park, B., \& Judd, C. M. (1990). Measures and models of perceived group variability. Journal of Personality and Social Psychology, 59, 173-191.

Rubini, M., \& Sigall, H. (2002). Taking the edge off of disagreement: Linguistic abstractness and self-presentation to a heterogeneous audience. European Journal of Social Psychology, 32, 343-351.

Ruscher, J. B., \& Lawson Duval, L. (1998). Multiple communicators with unique target information transmit less stereotypical impressions. Journal of Personality and Social Psychology, 74, 329-344.

Schaller, M., \& Conway, L. G., III. (1999). Influence of impression-management goals on the emergent contents of group stereotypes: Support for a social-evolutionary process. Personality and Social Psychology Bulletin, 25, 819-833.

Sedikides, C. (1990). Effects of fortuitously activated constructs versus activated communication goals on person impressions. Journal of Personality and Social Psychology, 58, 397-408.

Semin, G. R., \& Fiedler, K. (1988). The cognitive functions of linguistic categories in describing persons: Social cognition and language. Journal of Personality and Social Psychology, 54, 558-568.

Semin, G. R., \& Fiedler, K. (1989). Relocating attributional phenomena within a language-cognition interface: The case of actors' and observers' perspectives. European Journal of Social Psychology, 19, 491-508.

Semin, G., \& Fiedler, K. (1991). The linguistic category model, its bases, applications and range. In W. Stroebe \& M. Hewstone (Eds.), European Review of Social Psychology, 2 (pp. 1-30). Chichester, UK: Wiley.

Semin, G., \& Fiedler, K. (1992). The inferential properties of interpersonal verbs. In G. Semin \& K. Fiedler (Eds.), Language, interaction and social cognition (pp. 58-78). Newbury Park, CA: Sage.

Semin, G. R., Gil de Montes, L., \& Valencia, J. F. (2003). Communication constraints of strategic language use. Journal of Experimental Social Psychology, 39, 142-148.

Spears, R., Oakes, P. J., Ellemers, N., \& Haslam, S. A. 
(Eds.). (1997). The social psychology of stereotyping and group life. Oxford, UK: Blackwell.

Stangor, C., \& Lange, J. E. (1994). Mental representations of social groups: Advances in understanding stereotypes and stereotyping. In M. P. Zanna (Ed.), Advances in experimental social psychology (Vol. 26, pp. 357-416). New York: Academic Press.

Stangor, C., \& McMillan, D. (1992). Memory for expectancy-congruent and expectancyincongruent information: A review of the social and social developmental literatures. Psychological Bulletin, 111, 42-61.

Taylor, S. E. (1981). A categorization approach to stereotyping. In D. Hamilton (Ed.), Cognitive processes in stereotyping and intergroup behavior (pp. 83-114). Hillsdale, NJ: Erlbaum.

Turner, J. C., Oakes, P. J., Haslam, S. A., \& McGarty, C. (1994). Self and collective: Cognition and social context. Personality and Social Psychology Bulletin, 20, 454-463.

Van Knippenberg, A., \& Dijksterhuis, A. (2000). Social categorization and stereotyping: A functional perspective. European Review of Social Psychology, 11, 105-144.

von Hippel, W., Sekaquaptewa, D., \& Vargas, P. (1997). The linguistic intergroup bias as an implicit indicator of prejudice. Journal of Experimental Social Psychology, 33, 490-509.

Wigboldus, D. H. J., Semin, G. R., \& Spears, R. (2000). How do we communicate stereotypes? Linguistic bases and inferential consequences. Journal of Personality and Social Psychology, 78, 5-18.

Paper received 2 February 2004; revised version accepted 31 January 2005.

\section{Biographical notes}

DANIËL H. J. WIGBOLDUS is professor of social psychology at the Radboud University Nijmegen. His main research interest is in the interface of interpersonal and intrapersonal social cognitive processes, especially with respect to stereotyping. Currently, he is also involved in research on intergroup emotions and research on the malleability of implicit associations.

RUSSELL SPEARS is professor of social psychology at Cardiff University, Wales. He also holds honorary professor positions in Manchester and Amsterdam. His research interests are in social identity and intergroup relations (especially intergroup discrimination, and the role of emotions and automatic processes in intergroup behavior), social stereotyping and self-categorization processes, and social influence and power (especially as applied to computer-mediated communication).

GÜN R. SEMIN is currently Academy Professor of The Netherlands Royal Academy of Arts and Sciences and is located at the Free University, Amsterdam. His primary research interest is in language, cognition and communication with different conceptual applications (e.g. culture, group contexts, individual differences, automatic evaluation processes) constituting extended applications of this primary focus. 